\title{
INFLUÊNCIA DOS ENXAGUATÓRIOS BUCAIS NA RUGOSIDADE SUPERFICIAL DE UMA RESINA COMPOSTA
}

\author{
INFLUENCE OF MOUTHWASHES ON SURFACE \\ ROUGHNESS OF A COMPOSITE RESIN
}

Gabriela Sampaio Aragão*, Renata Martins Falcão*, Íris Durães**, Rebeca Barroso Bezerra***

Autora para correspondência: Gabriela Sampaio Aragão-gabiaragao2@hotmail.com

*Acadêmica de Odontologia da Universidade Federal da Bahia

**Professora do Núcleo de Clínica Integrada de Atenção Básica da União Metropolitana de Educação e

Cultura - UNIME

***Doutora em Odontologia pela USP. Professora na Universidade Federal da Bahia

\section{RES U M O}

\begin{abstract}
A lisura superficial é uma importante característica do material restaurador. Dessa forma, a resina composta deve apresentar níveis de rugosidade baixos para dificultar a retenção de biofilme dental. A alteração da superfície das restaurações de resina composta pode estar associada às bebidas e alimentos ácidos, aos componentes da saliva, aos métodos de acabamento e polimento, assim como a ação de agentes clareadores, enxaguatórios e fluoretos. Objetivo: Avaliar o efeito de enxaguatórios bucais na rugosidade superficial de uma resina composta nanoparticulada por meio de uma avaliação quantitativa. Materiais e Métodos: Foram confeccionados 48 corpos de prova com a resina composta

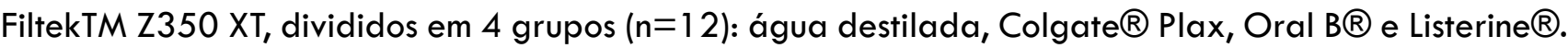
Para a confecção dos corpos de prova utilizou-se uma matriz retangular com perfurações, cada uma medindo $0,8 \mathrm{~cm}$ de diâmetro interno por $0,2 \mathrm{~cm}$ de espessura. Os corpos de prova foram imersos em $50 \mathrm{ml}$ de uma dessas substâncias, por 12 horas, equivalente a um ano de uso diário da solução por 2 minutos. Em seguida, foram armazenados em água destilada até a leitura no rugosímetro. Os dados encontrados foram tratados estatisticamente pelos testes de ANOVA e Tukey, com nível de significância de 95\%. Resultados: Foi observada diferença estatisticamente relevante entre o grupo controle e o Listerine ${ }^{\circledR}(p=0,03)$. Ao comparar as médias de rugosidade das diferentes marcas de enxaguatórios, não houve diferença estatisticamente significante $(p>0,05)$. Conclusões: Dentre os enxaguatórios

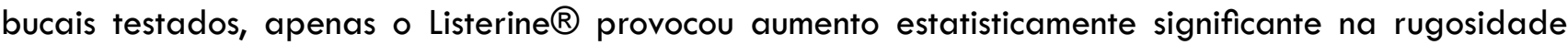
superficial da resina composta utilizada.
\end{abstract}

Palavras-chave: Antissépticos bucais, resinas compostas, placa dentária 
Surface smoothness is an important feature of restorative material. Thus, composite roughness levels should be low to make retention of dental biofilm. Alterations of the surface of composite resin restorations can be associated to drinks and acidic foods, components of saliva, finishing and polishing methods, as well as the action of bleaching agents, rinses and fluoride. Purpose: To evaluate the effect of mouth rinses in superficial roughness of composite resin through a quantitative evaluation. Methods: 48 specimens with composite resin FiltekTM Z350 XT were made and divided into 4 groups $(n=12)$ : distilled water, Colgate $\circledR$ Plax, Oral $B \circledR$ and Listerine $\circledR$. Specimens were made using a rectangular matrix with holes, each measuring $0.8 \mathrm{~cm}$ of internal diameter and $0.2 \mathrm{~cm}$ in thickness. The specimens were immersed in $50 \mathrm{ml}$ of each substance, for 12 hours, to simulate a year of daily use of the solution for 2 minutes. Then specimens were stored in distilled water until reading of the roughness tester. Data were statistically treated by ANOVA and Tukey tests, with a significance level of $95 \%$. Results: No statistically significant difference was observed between the control group and Listerine ${ }^{\circledR}(p=0.03)$. When comparing the average roughness of different brands of mouthwashes, there was no statistically significant difference $(p>0.05)$. Conclusions: Among the mouthwashes tested, only Listerine ${ }^{\circledR}$ caused statistically significant increase in superficial roughness of the composite resin used.

Keywords: Mouthwashes, composite resins, dental plaque 


\section{INTRODUÇÃO}

A estética e a preocupação com a aparência são fatores que interferem no convívio social, além de proporcionarem uma significativa melhora na autoestima do indivíduo. Isso explica o porquê do aumento da procura por restaurações que assegurem naturalidade, biocompatibilidade, durabilidade e custo acessível1. Para garantir 0 sucesso do procedimento, materiais estéticos como as resinas compostas, passam por avanços tecnológicos que visam a melhoria das suas propriedades físicas e mecânicas, destacando-se a contração de polimerização, cor, translucidez e lisura superficial ${ }^{2,3}$.

A lisura superficial é uma importante característica do material restaurador. A resina composta, portanto, deve apresentar níveis de rugosidade e porosidade baixos e ser altamente polida para dificultar a retenção de biofilme dental4. A alteração da superfície das restaurações de resina composta pode estar associada às bebidas e alimentos ácidos, aos componentes da saliva, aos métodos de acabamento e polimento, assim como a ação de agentes clareadores, enxaguatórios e fluoretos ${ }^{5-8}$.

O aumento da rugosidade do material restaurador, provocado pelo contato com essas substâncias, tem um grande impacto na adesão inicial e retenção de microrganismos orais, acelera a maturação do biofilme e pode resultar em cárie secundária e inflamação do tecido gengival, gerando, como consequência, $\circ$ insucesso da restauração9,10. Além disso, a presença de irregularidades da superfície decorrentes de polimentos e acabamentos inadequados resulta em problemas clínicos como manchamento do material resinoso, descoloração e acúmulo de placa bacteriana ${ }^{1}$.

Desse modo, uma superfície lisa e bem polida pode aumentar a longevidade e qualidade das restaurações com resina composta, propiciando um melhor controle sobre a textura, brilho e a preservação estética da restauração com a manutenção da $\operatorname{cor}^{12,13}$.

Os enxaguatórios bucais são frequentemente utilizados para prevenir e controlar a cárie, halitose e doenças periodontais ${ }^{14}$. A formulação destes antissépticos consiste em água, agentes anti-microbianos, sais e, em alguns casos, álcool, e as diferentes concentrações dessas substâncias podem afetar $\circ \mathrm{pH}$ na cavidade bucall 5 . Algumas propriedades físicas e mecânicas das resinas compostas são alteradas em razão do baixo $\mathrm{pH}$ e $\circ$ maior teor de álcool presente nos enxaguatórios bucais ${ }^{14,16}$. Contudo, os efeitos de tais componentes nas resinas compostas são amplamente discutidos ${ }^{15-17}$, já que a sua composição pode influenciar na susceptibilidade à degradação das restaurações ${ }^{17,18}$.

As diferentes quantidades, tamanhos e distribuição das partículas de carga têm um impacto direto na lisura da superfície do material restaurador 10. $\mathrm{Na}$ tentativa de reduzir a rugosidade superficial das resinas compostas, a fim de se obter melhores propriedades físicas, mecânicas e ópticas, os fabricantes têm diminuído o tamanho médio das partículas inorgânicas ${ }^{19}$. Atualmente, uma nova categoria de resinas compostas foi desenvolvida e introduzida no mercado, utilizando uma tecnologia de nanopartículas que reduzem a contração de polimerização e favorecem uma lisura superficial satisfatória ${ }^{17}$.

Em relação à influência dos enxaguatórios bucais na rugosidade superficial da resina composta, os dados encontrados na literatura são muito diversos e, diante disso, faz-se necessária a realização de novos estudos, utilizando-se métodos qualitativos e/ ou quantitativos, no intuito de promover uma melhor análise do comportamento dessas substâncias.

Dessa forma, o presente trabalho visa avaliar, in vitro, o efeito de enxaguatórios bucais na rugosidade superficial de uma resina composta nanoparticulada por meio de uma avaliação quantitativa (rugosímetro).

\section{MATERIAIS E MÉTODOS}

Para a realização deste estudo foi utilizada uma resina composta nanoparticulada FiltekTM Z350 XT (3M ESPE, St. Paul, MN, USA) na cor B2 e três enxaguatórios bucais: Colgate $\AA$ Plax (Colgate/ 
Palmolive, São Bernardo do Campo, São Paulo, Brasil), Oral ${ }^{\circledR}$ B (Procter \& Gamble, Queimados, Rio de Janeiro, Brasil) e Listerine ${ }^{\circledR}$ (Johnson \& Johnson Ltda, São José dos Campos, São Paulo, Brasil), conforme as Figuras 1 e 2. Os materiais encontram-se relacionados nas Tabelas 1 e 2, de acordo com suas especificações.

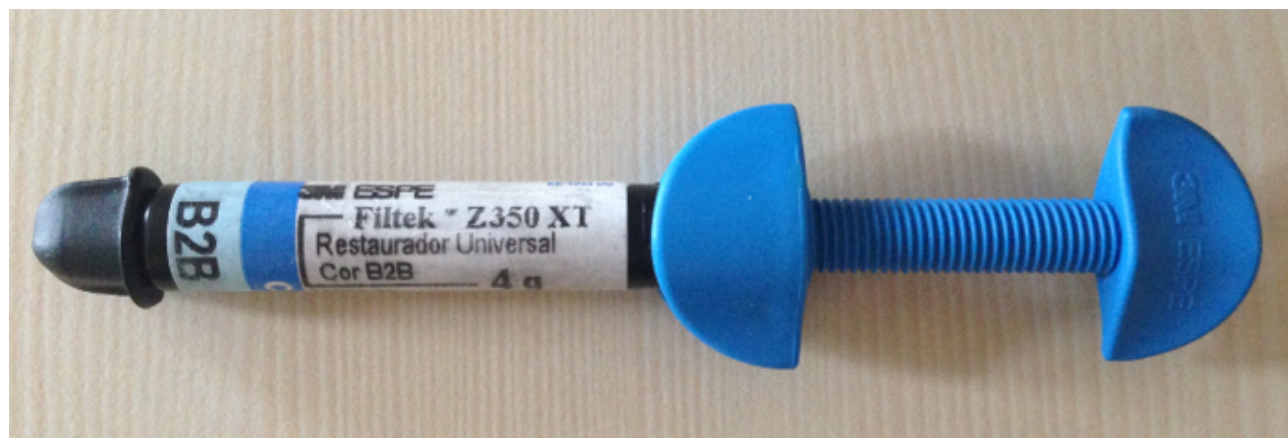

Figura 1. Resina composta FiltekTM Z350 XT

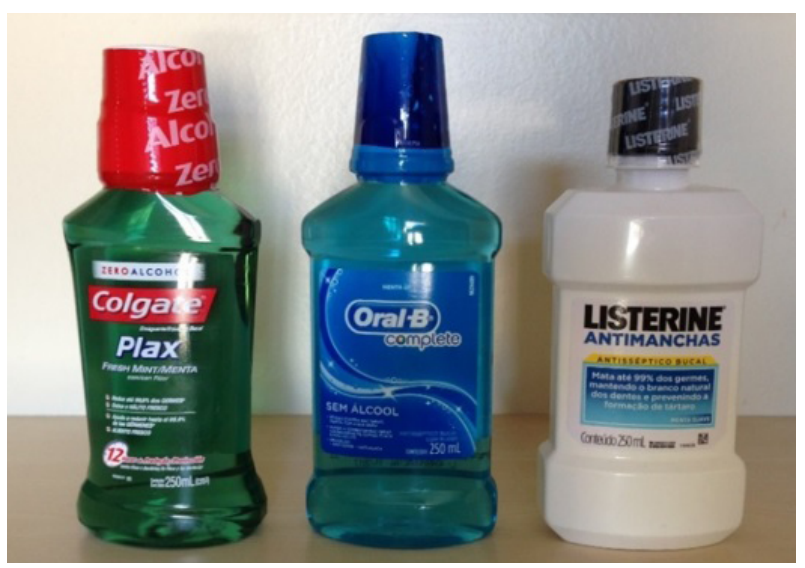

Figura 2. Enxaguatórios bucais utilizados

Tabela 1. Especificação da resina composta utilizada no estudo de acordo com o perfil técnico do fabricante

\begin{tabular}{|c|c|c|c|c|}
\hline Material & Tipo & Monômeros & $\begin{array}{c}\text { Partículas de carga } \\
\text { Tamanho }\end{array}$ & $\begin{array}{l}\text { Partículas } \\
\text { inorgânicas } \\
\% \text { em peso/ } \\
\text { volume }\end{array}$ \\
\hline $\begin{array}{c}\text { Filtek }^{T M} \text { Z350 } \\
\text { XT }\end{array}$ & Nanoparticulada & $\begin{array}{c}\text { Bis-GMA, } \\
\text { UDMA, } \\
\text { TEGDMA e Bis- } \\
\text { EMA }\end{array}$ & $\begin{array}{c}\text { Sílica }-20 \mathrm{~nm} \\
\text { Zircônia }-4-11 \mathrm{~nm} \\
\text { Aglomerados }-0.6-10 \mu \mathrm{m}\end{array}$ & $78,5 / 63,3$ \\
\hline
\end{tabular}

Tabela 2. Composição dos enxaguatórios bucais utilizados no estudo de acordo com as informações do fabricante

\begin{tabular}{cc}
\hline Enxaguatório & Composição \\
\hline Colgate $^{\circledR}$ Plax & $\begin{array}{r}\text { Água, Glicerina, Propilenoglicol, Sorbitol, PEG-40 Oléo Hidrogenado, Cloreto de } \\
\text { Cetilpiridínio, Sacarina sódica, Fluoreto de sódio, Gantrez }\end{array}$ \\
\hline Oral-B ${ }^{\circledR}$ Complete & $\begin{array}{r}\text { Ȧgua, Glicerina, PEG-40 Oléo Hidrogenado, Metilparabeno, Aroma, Sacarina sódica, } \\
\text { Benzoato de sódio, Propilparabeno, Cl 42090, Cloreto de Cetilpiridínio Monohidratado, } \\
\text { Fluoreto de sódio }\end{array}$ \\
\hline $\begin{array}{c}\text { Listerine }{ }^{\circledR} \text { Whitening } \\
\text { Antimanchas }\end{array}$ & $\begin{array}{r}\text { Timol, Eucaliptol, Mentol Salicilato, Mentol, Água, Álcool, Sorbitol, Aroma, Poloxâmero 407, } \\
\text { Sacarina Sódica, Ácido benzoico, Cloreto de zinco, Benzoato de sódio }\end{array}$ \\
\hline
\end{tabular}


Para a confecção dos corpos de prova, a resina foi inserida com $\circ$ auxílio de uma espátula de inserção em uma matriz de alumínio retangular com $12 \mathrm{~cm}$ de comprimento, $3,5 \mathrm{~cm}$ de largura e $0,2 \mathrm{~cm}$ de espessura, possuindo 5 perfurações, cada uma medindo $0,8 \mathrm{~cm}$ de diâmetro interno por $0,2 \mathrm{~cm}$ de espessura, que determinaram as dimensões dos espécimes. Para a obtenção de uma superfície lisa com $\circ$ polimento natural da resina, a matriz foi colocada sobre uma placa de vidro vaselinada e sobre a resina composta foi colocada uma lâmina de vidro utilizada para microscopia $(75 \mathrm{~mm} \times 50$ $\mathrm{mm} \times 1 \mathrm{~mm}$ ), sendo interposta entre ela e a lâmina uma tira de poliéster (Figura 3). Para facilitar a remoção dos corpos de prova da matriz metálica, as superfícies internas das perfurações foram isoladas com vaselina líquida.
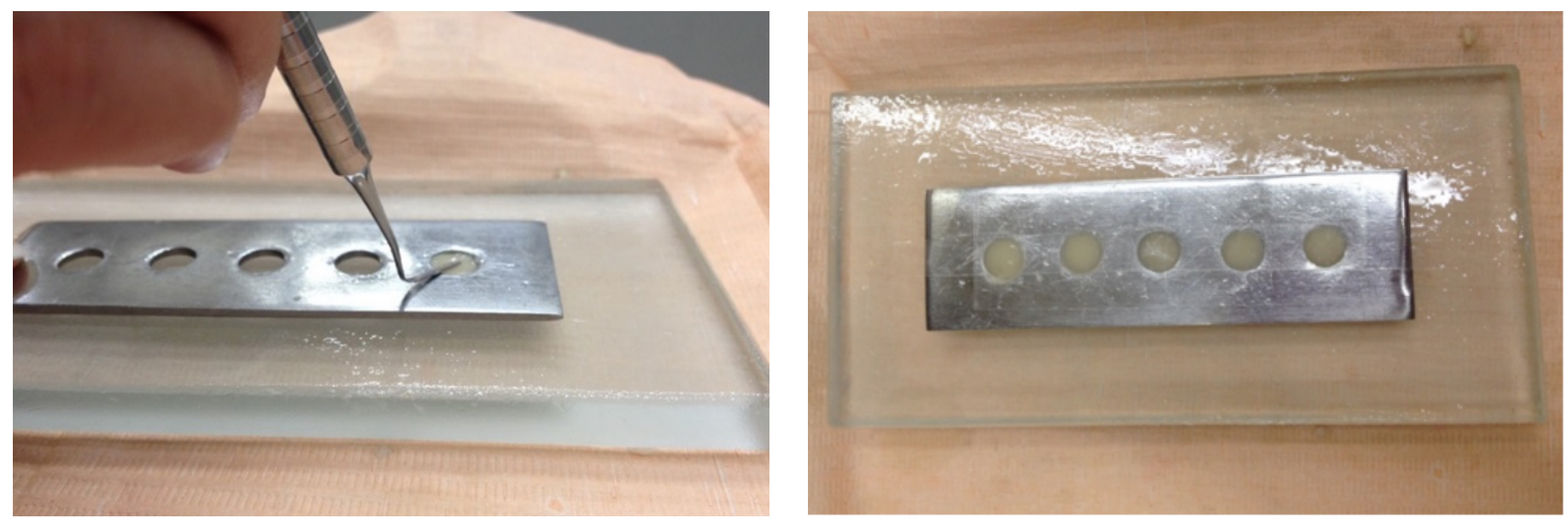

Figura 3. Confecção dos corpos de prova

A resina foi fotoativada seguindo as recomendações do fabricante, por 20 segundos, expondo a superfície total a uma fonte de luz LED de alta intensidade com o aparelho fotopolimerizador DB-686 (Dabi Atlante, Ribeirão Preto, São Paulo, Brasil), mantendo sempre a ponta polimerizadora o mais próximo possível do espécime durante a exposição do material à luz (Figura 4).

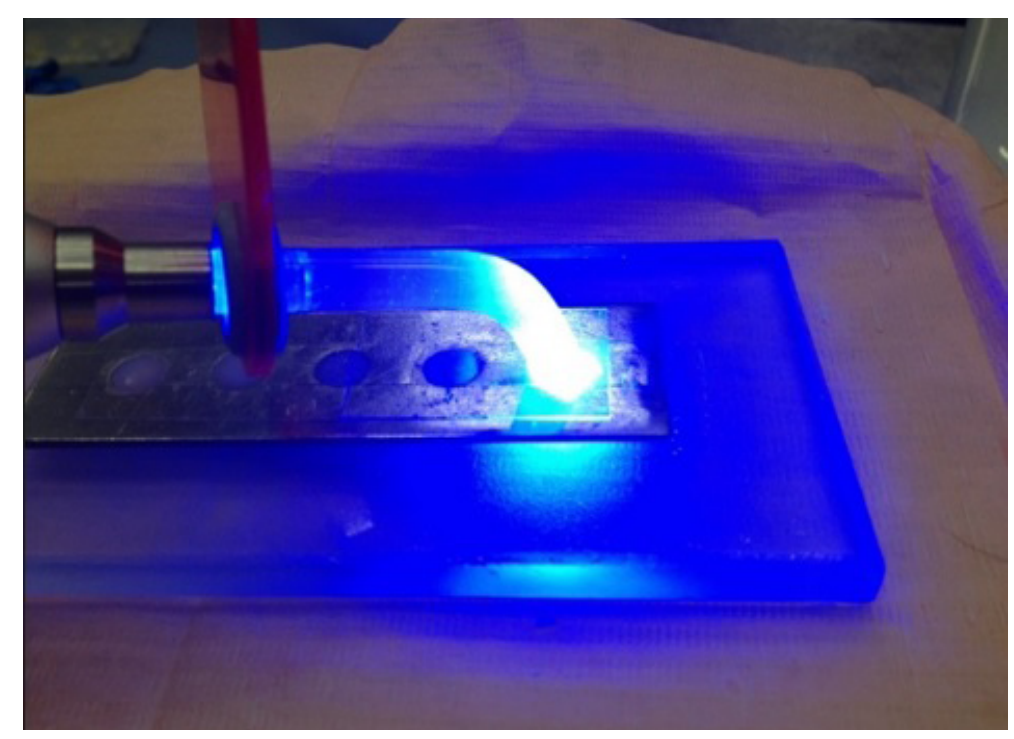

Figura 4. Fotopolimerização dos corpos de prova 
Foram confeccionados 48 corpos de prova em resina composta, por um único operador, sendo cada grupo experimental composto de 12 espécimes, a saber: Grupo 1 - água destilada (controle positivo); Grupo 2- enxaguatório Colgate ${ }^{\circledR}$ Plax; Grupo 3enxaguatório Oral $B \circledR$ e Grupo 4- enxaguatório Listerine ${ }^{\circledR}$.

Após confeccionados, cada grupo experimental foi imerso em $50 \mathrm{ml}$ de uma das soluções, por 12 horas, equivalente a um ano de uso diário da solução por 2 minutos ${ }^{20}$. Os grupos dos enxaguatórios foram agitados a cada hora, com $\circ$ intuito de evitar $\circ$ equilíbrio químico na superfície da restauração e mantidos em temperatura ambiente. Em seguida, foram armazenados em água destilada sob mesma temperatura até a leitura no rugosímetro.
As medidas de rugosidade superficial foram obtidas com o auxílio do rugosímetro digital SJ 301 (Mitutoyo, Kawasaki, Kanagawa, Japão), que foi calibrado de acordo com as instruções contidas no manual do equipamento (Figura 5). Os espécimes foram secados e fixados com cola instantânea em uma placa de vidro para evitar o seu deslocamento (Figura 6). $O$ aparelho possui uma ponta diamantada específica com tamanho de $0,5 \mathrm{~mm}$ de raio que se desloca a uma velocidade de $0,25 \mathrm{~mm} / \mathrm{s}$. A ponta do aparelho foi programada para percorrer uma distância de $4 \mathrm{~mm}$, com comprimento de onda de $0,8 \mathrm{~mm}$ e ajuste de rugosidade superficial média em unidade de micrômetros $(\mu \mathrm{m})$. Cada corpo de prova foi submetido a três leituras, uma em cada direção, no intuito de varrer toda a amostra.

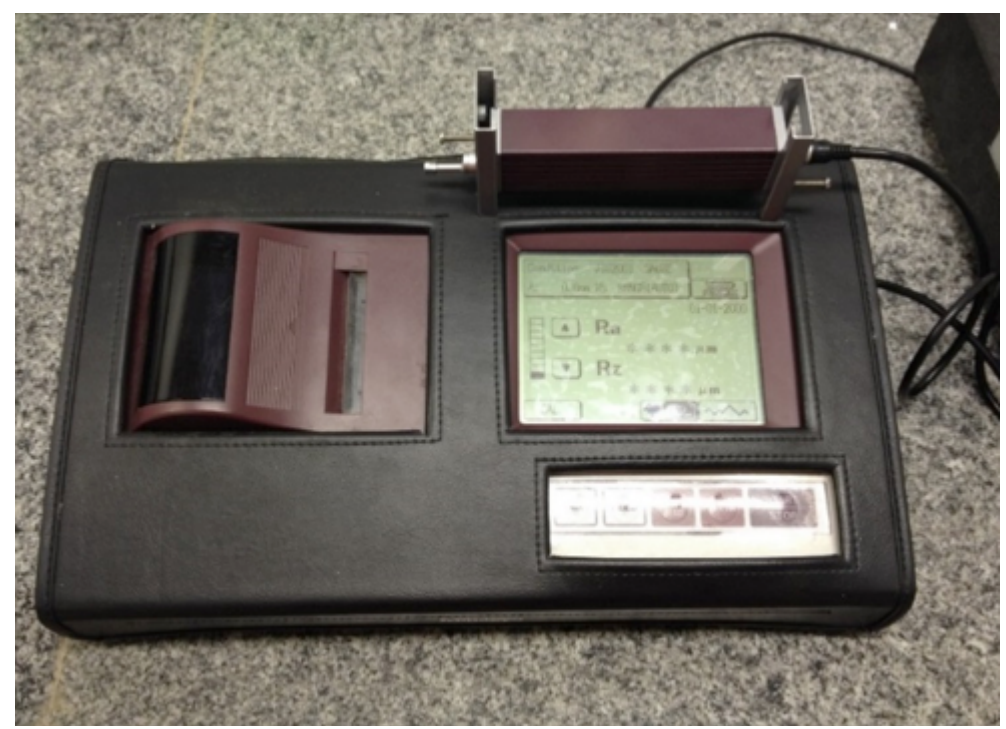

Figura 5. Rugosímetro digital SJ 301

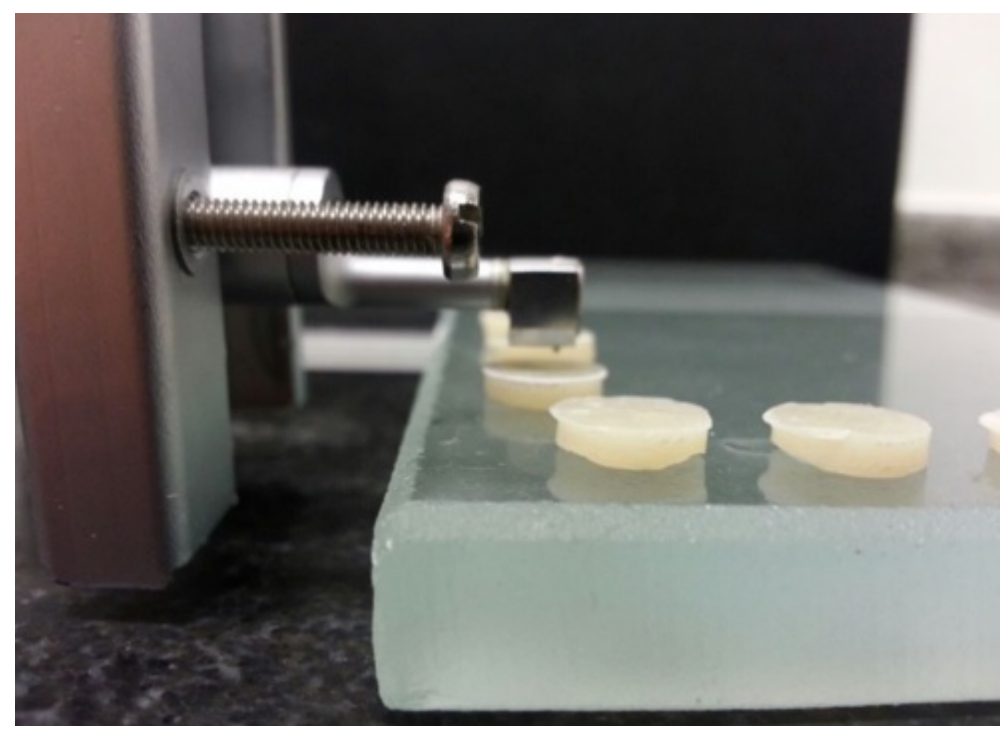

Figura 6. Corpos de prova fixados para leitura 
O valor considerado foi a média aritmética $(R a)$ entre os picos e vales percorridos pela ponta ativa do aparelho. As médias dos valores obtidos foram anotadas, tabuladas e submetidas à análise estatística. Os dados encontrados foram tratados estatisticamente pela análise de variância ANOVA (one-way) e pelo teste de Tukey, com nível de significância de 95\%.

\section{RESULTADOS}

Os valores médios de rugosidade $(\mathrm{Ra}, \mu \mathrm{m})$ e desvios-padrão de cada grupo, bem como os resultados do teste de Tukey, estão apresentados na Tabela 3.

Tabela 3. Média de rugosidade $(\mu \mathrm{m})$ e desvio padrão dos grupos experimentais

\begin{tabular}{ccc}
\hline Grupos & Média de rugosidade & Desvio padrão \\
\hline CONTROLE & 0,50 a & 0,22 \\
\hline COLGATE ${ }^{\circledR}$ PLAX & 0,96 a b & 0,44 \\
\hline ORAL $B^{\circledR}$ COMPLETE & 0,97 a b & 0,73 \\
\hline $\begin{array}{c}\text { LISTERINE }{ }^{\circledR} \text { WHITENING } \\
\text { ANTIMANCHAS }\end{array}$ & 1,16 b & 0,63 \\
\hline *Letras minúsculas diferentes representam significância estatística pelo teste de Tukey. Médias seguidas pela mesma letra são
\end{tabular}
estatisticamente semelhantes.

Pôde-se avaliar maior média de rugosidade nos corpos de prova imersos em solução de Listerine $\gtrless_{\text {, havendo }}$ diferença estatisticamente relevante quando comparados ao grupo Controle $(p=0,033)$. Ao comparar as médias de rugosidade das diferentes marcas de enxaguatórios, observou-se que as mesmas apresentaram valores estatiscamente iguais $(p>0,05)$.

\section{DISCUSSÃO}

Para que haja sucesso no tratamento restaurador, os princípios físicos e mecânicos devem ser adotados e respeitados. Entretanto, a longevidade e integridade da restauração são influenciadas por fatores químicos e biológicos ${ }^{21,22}$.

O aumento do número de pessoas que fazem uso constante dos enxaguatórios bucais deve-se, principalmente, ao fato de ser uma medida auxiliar à escovação, além de atuar contra halitose e proporcionar sensação refrescante ${ }^{14,23}$.

Em contrapartida, o seu uso indiscriminado é preocupante, devido aos componentes ácidos presentes na sua formulação, podendo, ainda, ser prejudicial aos tecidos bucais a longo prazo ${ }^{24}$.

O álcool é um componente presente em alguns antissépticos bucais e caracteriza-se por ser um bom solvente da cadeia de polímeros da resina composta. Quando encontrado em elevadas concentrações, pode reduzir as propriedades mecânicas e favorecer o desgaste do material restaurador ${ }^{14,16,25}$.

No presente estudo, os enxaguatórios Colgate Plax ${ }^{\circledR}$ e Oral $B \circledR$ não promoveram aumento estatisticamente relevante da rugosidade superficial da resina composta analisada. Este resultado pode ser justificado pela ausência de álcool na composição desses antissépticos. 
Já $\circ$ enxaguatório Listerine $\AA_{\text {, em }}$ cuja composição há presença de álcool, provocou aumento estatisticamente significante da rugosidade superficial da resina composta FiltekTM Z350 $X T$, corroborando com os achados obtidos por Hama rassul et al. ${ }^{25}$. Tal resultado difere do encontrado por Lucena et al. ${ }^{5}$, no qual nenhum dos antissépticos analisados, dentre eles $\circ$ Listerine ${ }^{\circledR}$, causaram alterações estatisticamente relevantes na rugosidade superficial do material restaurador avaliado. Vale ressaltar que nos dois estudos os espécimes foram submetidos à ação das substâncias pelo mesmo período de tempo.

Segundo Bollen et al. ${ }^{9}$, a superfície de uma restauração deve apresentar a maior lisura possível, sendo o limiar clinicamente aceitável para a rugosidade superficial de restaurações com resina composta de 0,2 $\mu \mathrm{m}$. Dessa forma, valores acima disso propiciam a retenção do biofilme dental e maior risco de doença periodontal e cárie dentária. No presente estudo, o enxaguatório Listerine apresentou valor de rugosidade superficial estatisticamente significante em relação ao grupo Controle. Entre os grupos de enxaguatórios, os resultados de rugosidade superficial obtidos não apresentaram diferença estatisticamente relevante. Entretanto, os valores encontrados para todos os grupos foram acima do limiar clinicamente aceitável proposto por Bollen et al.?.

Além de interferir na rugosidade superficial, a ação dos enxaguatórios bucais interfere na dureza das resinas compostas ${ }^{14,21,23}$. Gonçalves et al. ${ }^{21}$ avaliaram $\circ$ efeito de três antissépticos bucais sobre a microdureza de uma resina composta nanoparticulada e verificaram que a solução de Listerine $\AA$ diminuiu a dureza superficial do material estudado. Tal resultado apoia o encontrado por Miranda et al. ${ }^{14}$, no qual observaram que as resinas compostas testadas sofreram alterações na dureza da superfície após imersão em enxaguatórios bucais contendo álcool. Estes achados corroboram com os resultados obtidos no presente trabalho no que diz respeito à influência negativa dos antissépticos bucais contendo álcool nas propriedades físicas das resinas compostas.

Segundo Trauth et al. ${ }^{26}$, a rugosidade superficial de uma resina composta nanoparticulada pode ser alterada por antissépticos bucais quando associada à escovação, porém, apenas a solução de bochecho não influencia na rugosidade da superfície. Estes resultados diferem do presente estudo, cuja rugosidade superficial dos espécimes que foram submetidos apenas a ação dos enxaguatórios bucais apresentou-se aumentada em todos os grupos.

tempo de exposição e a substância química utilizada são fatores determinantes na alteração da superfície dos materiais restauradores ${ }^{17,18}$. Foi observado que o uso diário de enxaguatórios bucais por 2 minutos, durante um ano, promove aumento da rugosidade superficial da resina composta. Além disso, a substância contendo álcool apresentou diferença estatisticamente significante de rugosidade de superfície quando comparada ao grupo Controle.

Urbano et al. ${ }^{27}$ e Bohner et al. ${ }^{28}$ afirmaram que independentemente da formulação, os antissépticos bucais não modificam a rugosidade da superfície da resina composta durante o período de 30 dias. Em contrapartida, Miranda et al. ${ }^{14}$ asseguraram que enxaguatórios bucais contendo álcool apresentam maior potencial para modificar a rugosidade superficial, além da duração do tempo de imersão interferir na rugosidade da superfície dos compósitos.

Ainda há controvérsias na literatura no que diz respeito à influência dos antissépticos bucais nas propriedades mecânicas e físicas das resinas compostas ${ }^{5,14,16,26,27}$. Isso se deve a outros fatores que interferem nas propriedades do material, como hábitos de higiene bucal, composição salivar, alimentação e presença de biofilme ${ }^{14,20}$. Desse modo, os enxaguatórios bucais podem apresentar clinicamente efeitos diferentes dos analisados ${ }^{21}$.

Os estudos in vivo favorecem a obtenção de resultados abrangendo diversas variáveis, enquanto a utilização de estudos in vitro são de grande relevância quando se deseja analisar isoladamente um único fator, sem a influência de outras variáveis. Nesse contexto, novos estudos in vivo e in vitro são recomendados para avaliar os fatores que possam interferir no comportamento da resina composta quando submetida aos efeitos dos diversos antissépticos bucais. 


\section{CONCLUSÕES}

Com base na metodologia empregada pôdese concluir que, dentre os enxaguatórios bucais testados, apenas $\circ$ Listerine $₫$ provocou aumento estatisticamente significante na rugosidade superficial da resina composta FiltekTM Z350 XT.

Não houve diferença estatisticamente relevante entre as médias de rugosidade superficial dos enxaguatórios bucais do presente estudo.

\section{REFERÊNCIAS}

1. Montemezzo SL, Silva FB, Martin JMH, Bondarczuk $A B$, Vaz MAK. Onlay em cerômero - uma revisão aplicada à clínica. PCL 2004;6(32): 396-408

2. Júnior PCM, Cardoso RM, Magalhães BG, Guimarães RP, Silva CHV, Beatrice LCS. Selecionando corretamente as resinas compostas. In J Dent. $2011 ; 10(2): 91-6$

3. Pereira DF, Bevilacqua FM, Boscarioli ANT, Felício $C M$, Secco AS. Avaliação da microdureza e rugosidade superficial de uma resina composta submetida ao clareamento com peróxido de hidrogênio a $35 \%$. J Health Sci Inst. $2012 ; 30(4): 323-6$

4. Queiroz RS, Boa Sorte D, Silva $M A B$, Ribeiro $B C l$, Porto-Neto ST, Andrade MF. Análise comparativa da rugosidade superficial de resinas compostas de alta densidade. Rev Sul-Bras Odontol. 2010;7(4):414-21

5. Lucena MCM, Gomes RVS, Santos MCMS. Avaliação da rugosidade superficial da resina composta Filtek Z350 3M/ Espe de baixa viscosidade exposta a enxaguatórios com e sem álcool. Odontol. Clín.-Cient. $2010 ; 9(1): 59-64$

6. Gouvea CVD, Bedran LM, Faria MA, Ferreira NC. Surface roughness and translucency of resin composites after immersion in coffee and soft drink. Acta Odontol. Latinoam. $2011 ; 24(1): 3-7$

7. Gonçalves MA, Teixeira VCF, Rodrigues SSMFG, Oliveira RSMF, Salvio LA. Evaluation of the roughness of composite resins submitted to different surface treatments. Acta Odontol. Latinoam. 2012 ;25(1):89-95
8. Taib FM, Ghani ZA, Mohamad D. Effect of home bleaching agents on the hardness and surface roughness of resin composites. Arch Orofac Sci. 2013;8(1):34-40

9. Bollen CM, Lambrechts P, Quirynen M. Comparison of surface of oral hard materials to the threshold surface roughness for bacterial plaque retention: a review of the literature. Dent Mater J. 1997;13(4):258-69

10. Venturini D, Cenci MS, Demarco FF, Camacho GB, Powers JM. Effect of polishing techniques and time on surface roughness, hardness and microleakage of resin composite restorations. Operative Dentistry. 2006;31(1):11-7

11. Karaarslan ES, Bulbul M, Yildiz E, Secilmis A, Sari $F$, Usumez A. Effects of different polishing methods on color stability of resin composites after accelerated aging. Dental Materials Journal. 2013;32(1):58-67. doi: $10.4012 / \mathrm{dmj} .2012-045$

12. Tapia LR, Amaral FLB, França FMG, Flório FM, Rodrigues JA, Basting RT. Rugosidade de resinas compostas submetidas a diferentes métodos de acabamento e polimento. Rev Odontol. 2012;41(4):254-9

13. Menezes MS, Vilela ALR, Silva FP, Reis GR, Borges MG. Acabamento e polimento em resina composta: reprodução do natural. Rev Odontol Bras Central. 2014;23(66):1 24-9

14. Miranda DA, Bertoldo CES, Aguiar FHB, Lima DANL, Lovadino JR. Effects of mouthwashes on Knoop hardness and surface roughness of dental composites after different immersion times. Braz Oral Res. $2011 ; 25(2): 168-73$

15. Almeida GS, Poskus LT, Guimarães JGA, Silva EM. The effect of mouthrinses on salivary sorption, solubility and surface degradation of a nanofilled and a hybrid resin composite. Operative Dentistry. 2010;35(1):10511. doi: 10.2341/09-080-L

16. Porto ICM, Neves LE, de Souza CK, Parolia A, dos Santos NB. A comparative effect of mouthwashes with different alcohol concentrations on surface hardness, sorption and solubility of composite resins. Oral Health Dent Manag. 2014;13(2):502-6

17. Rocha ACC, Lima CSA, Santos MCMS, Montes MAJR. Evaluation of surface roughness of a nanofill resin composite after simulated brushing and Immersion in mouthrinses, alcohol and water. Materials Research. 2010;13(1):77-80. doi: 10.1590/\$1516- 


\section{6}

18. Leite TM, Bohaienko LA, Luciano M, Pillati GL, Pereira SK. Influência de substâncias com pH ácido sobre a microdureza de resinas compostas. Stomatos. $2010 ; 16(30): 21-32$

19. Silva JMF, Rocha DM, Kimpara ET, Uemura ES. Resinas compostas: estágio atual e perspectivas. Revista Odonto. 2008;16(32):98-104

20. Gurgan S, Onen A, Koprulu H. In vitro effects of alcohol containing and alcohol-free mouthrinses on microhardness of some restorative materials. J Oral Rehabil. 1997;24(3):244-6

21. Gonçalves AR, Tavares MJGM, Costa DA, Freire $A C M$, Souza CHC, Brandim AS et al. Influência de antissépticos bucais sobre a dureza de resinas compostas diretas. Rev Odontol Bras Central. 2014;23(65):100-3

22. Kinoshita RYO, Sgura R, Reis MC, Masuda MS, Prazeres PSL, Junior WR et al. Effect of whitening dentifrices on surface roughness of dental nanofillerbased composites. Stereomycroscopy and AFM analysis. Braz Dent. Sci. 2016;19(3):65-74. doi: 10.14295/ bds.2016.v19i3.1271

23. Festuccia MSCC, Garcia LFR, Cruvinel DR, Piresde-souza FCP. Color stability, surface roughness and microhardness of composites submitted to mouthrinsing action. J Appl Oral Sci. 2012;20(2):200-5

24. Poggi P, Baena RR, Rizzo S, Rota MT. Mouthrinses with alcohol: Cytotoxic effects on human gingival fibroblasts in vitro. J Periodontol. 2003;74(5):623-9. doi: 10.1902/jop.2003.74.5.623

25. Hama rasul HQ, Al-Qaisi SD, Alrahman MAS. Evaluating the effect of one alcoholic and two alcoholicfree mouthwashes on the color stability and surface roughness of two resin-based composites (In vitro comparative study). International Journal Of Scientific Research. 2015;4(10):254-7

26.Trauth KGS, de Godoi APT, Colucci V, Corona $S A M$, Catirse ABCEB. The influence of mouthrinses and simulated toothbrushing on the surface roughness of a nanofilled composite resin. Braz Oral Res. 201 2;26(3):209-14. doi: 10.1590/S180683242012000300005

27. Urbano CD, Abrahão ALS, Lancellotti AC, MenezesOliveira MAH, Calabrez S, Gonçalves LS. Effect of mouthrinses on the surface roughness of nanofilled composite. Braz Dent Sci. 2014;17(3):92-7. doi: $10.14295 /$ bds.2014.v17i3.1014

28. Bohner LOL, de Godoi APT, Ahmed AS, Neto PT, Catirse ABCEB. Surface roughness of restorative materials after immersion in mouthwashes. Eur J Gen Dent. 2016;5:111-4 